\title{
OSWALDO FROTA-PESSOA (1917-2010): A successful three-lane road in science
}

A week before his 93rd birthday, Professor Oswaldo Frota-Pessoa passed away in the city of São Paulo, Brazil. Born in Rio de Janeiro on March 30, 1917, into an intellectually gifted family, "Frota", as he was called by most people who knew him, graduated in Natural History in 1938 and in Medicine in 1941. The Natural History course at the University of the Federal District, newly organized by the educator Anisio Teixeira, was aimed at educating science teachers and research naturalists and deeply influenced Frota's professional life, both as researcher and educator. Based on research projects, the course captivated Frota, and even before graduating he published his first scientific paper, on the taxonomy of a family of plants from the State of Rio de Janeiro. Immediately after graduation in Natural History, he started working as a part-time high-school science teacher, a job he held until 1958. In 1942, he was working at the currently named Institute of Biology of the Federal University of Rio de Janeiro, where he later on became a part-time staff member (1947 to 1958). In 1958, he

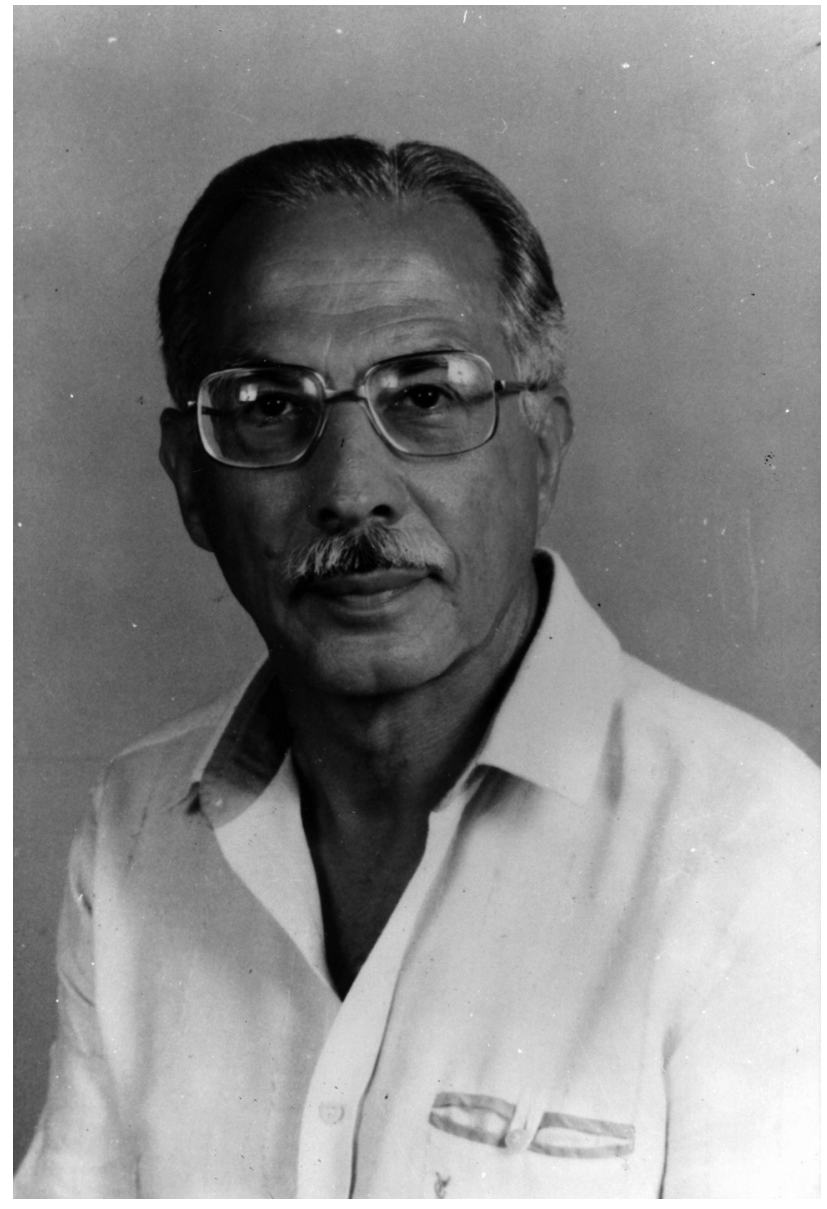

moved to São Paulo, following an invitation of Crodowaldo Pavan, then head of the Department of Biology (nowadays the Department of Genetics and Evolutionary Biology, Institute of Biosciences) of the University of São Paulo, where he started a successful academic career that lasted until 1981, when he retired as a full professor.

Although he soon showed interest in genetics, motivating him to publish a review of the notions of inheritance in ancient Greece and Rome and a mathematical analysis of Mendelian segregation, in the early 1940's, Frota began his research career as a taxonomist. In 1943, he had the chance to meet Theodosius Dobzhansky at André Dreyfus' laboratory in the Department of Biology of the University of São Paulo. Dobzhansky and Crodowaldo Pavan were working there on a classification key for Brazilian Drosophilidae. This meeting had certainly a major influence on Frota's decision to specialize in the taxonomy of Drosophila; his $\mathrm{PhD}$ thesis, defended in 1954, dealt with the revision of the tripunctata group of Drosophila, to which he contributed with the description of 15 new species. In the meantime, he was granted a Rockefeller Foundation fellowship to work at Dobzhansky's laboratory at Columbia University, New York (1953-1955). Working with Drosophila pseudoobscura, he described the first X-linked mutation that changed the pigmentation of the testicular envelope without altering the eye color. In Frota's own words (Frota-Pessoa O., Living History-Biography: a rambling rationalist, Am J Med Genet 63:585, 1996), this discovery that came to be his last work on Drosophila was also his "baptism" in genetics. And his choice was human genetics when he became a staff member of the Department of Biology at the University of São Paulo. He actually had had some previous flirtation with this field when he investigated the causes of the high frequency of deafness in a small town in Goiás, Brazil. But Frota used to say that Newton Freire-Maia, the pioneer of human genetics in Brazil, had played a key part in his decision when he wrote the Dahlberg formula on the sands of the Flamengo beach in Rio de Janeiro and thereby led him to embark on the study of isolates. This was the subject of his Privat Docent thesis, presented in 1963. In 1964, pursuing the line of research on human population genetics, he joined JF Crow's Department in Wisconsin, USA, with a Fullbright one-year fellowship. And again there were circumstances which played a role in his professional choices, since his sharing a room with JM Opitz certainly inspired him to take the road towards medical genetics. Moreover, being in Wisconsin offered him the opportunity to learn human cytogenetics from two experts, Klaus Patau and Eeva Therman. Upon his re- 
turn to Brazil, he developed frantic activities in human and medical genetics. He started research in cytogenetics, but also addressing evolutionary aspects. A group of vertebrate cytogenetics investigators flourished under the direction of his former PhD student Yatiyo Yonenaga-Yassuda. Human and Medical Genetics became a main research line in the Department at the University of São Paulo. He moreover set up a Genetics Counseling Service that was not restricted to seeing patients and their families, but also intended to be a training center for graduate students. There, under his supervision, medical doctors obtained $\mathrm{MSc}$ and $\mathrm{PhD}$ degrees in Genetics. Some of these students came from other South American countries, sponsored by the Multinational Genetics Program of the Organization of the American States (OAS). At the time, Frota was the Director of its Brazilian Center (1968-1973) devoted to the training of those interested in human genetics. During this period, visiting professors, like David Klein, Norma C. Magnelli, John M. Opitz, Eduardo E. Castilla, Rafael Elejalde, George Fraser and others, brought their experience to Frota's laboratory. The Alfred Jurzikowyski Prize granted to Frota by the Brazilian National Academy of Medicine in 1989 was the acknowledgement of his relevant basic research and dedication towards the expanding of medical genetics in Brazil.

Frota was the author or coauthor of some 140 scientific articles published in prestigious journals. As common denominator, his articles delight their readers not only for their rich scientific content but also for the profound elegance of their original ideas. Under Frota's supervision, 32 master dissertations and 15 doctoral theses were defended, and many of his students became leading geneticists in Brazil and other South American countries. The human and medical genetics line of research and the genetic counseling center he started at the University of São Paulo expanded under the leadership of his also former students Mayana Zatz and ourselves (AMVM and PAO). Following our mentor's example, we also trained students who became independent researchers, three of which - Maria Rita Passos-Bueno, Carla Rosenberg and Regina C. MingroniNetto - are a warrant that human genetics will continue as a strong line of research in the Department of Genetics and Evolutionary Biology at the University of São Paulo, where they became faculty.

Another very special subject along Frota's professional road was the teaching of Science. In addition to his engagement in high-school teaching for almost 20 years, throughout most of his life he continued to teach summer courses for science teachers, always enhancing the practical, experimental and therefore motivating approach. During the years 1956-1957, he worked as an expert in science education for the OAS, in Washington, DC. This project was intended to improve teaching in Latin America through courses for qualifying leaders in education which, in turn, would expand the formation of other leaders. This plan never took off, but Frota devoted part of his time to the writ- ing of a high-school textbook (Biologia na Escola Secundária - Biology in High School) that greatly influenced the teaching of biology in Brazil. The basis of its success was precisely the problem approach, where facts and principles were introduced while discussing problems raised by situations which were well-known to the students. An updated three-volume edition, Caminhos da Vida (Pathways of Life), was published in 2001, and he was working on its third printing earlier this year. Aware of the importance of the students' interest in learning, Frota and collaborators wrote a special version of this textbook for the Brazilian Northeast (Biologia Nordeste), involving typically local situations. In collaboration with Myriam Krasilchik, from the School of Education of the University of São Paulo, he adapted the Biological Sciences Curriculum Study (BSCS) on ecology to fit Brazilian students, with Brazilian species replacing the North American species of the original text. He further wrote extensively on science education: books, teacher's guides and articles. He edited five books and translated eight others, and was involved in many Brazilian and international workshops and conferences on the teaching of biology. In his writings on education, Frota had many young collaborators, and, as he used to point out, this was a way of training new writers.

Frota also produced a huge amount of material in the field of science education and popularization, having published about 700 articles in newspapers and popular magazines, and another 20 articles on science history and politics. His activities in the field of science popularization were widely recognized, as proven by two prizes awarded to him: the Brazilian José Reis Prize for the Popularization of Science (1981) and the UNESCO International Karlinga Prize for Popularization of Science (1982).

Frota's honors included membership to the Brazilian Academy of Sciences, to the Academy of Science of the State of São Paulo and to the Brazilian National Order of Scientific Merit (Comendador). He was Professor Emeritus of the Institute of Biosciences of the University of São Paulo. He was consultant of the World Health Organization Expert Committee on Human Genetics (1961-1986), president of the Brazilian Society of Genetics (1968-1970), and the first president of the Latin American Genetics Association (1969-1971).

All of us who knew Frota personally were impressed not only by his energy and intelligence, but also by his professionalism. His rationalism was permeated by a great sensitivity for understanding both the abilities and the limitations of others. He always showed a friendly willingness to help colleagues and students alike with a clear-headed word of advice or a shrewd and timely suggestion on how to solve a problem. We miss him greatly.

Angela M. Vianna-Morgante Paulo A. Otto

Departamento de Genética e Biologia Evolutiva Instituto de Biociências, Universidade de São Paulo, SP, Brazil 